\title{
Ocorrência e distribuição de Chromobacterium violaceum (Schroeter) Bergonzini 1881, na Amazônia Central
}

\author{
Vera Lucia M. dos Santos Guarim ( ${ }^{\star}$ )
}

Resumo

Foi estudada a ocorrência de Chromobacterium violaceum em 67 amostras de água superficial de rios, lagos e igarapés da Amazônia Central. Os corpos de água investigados representam os 3 tipos de água da regiāo, propostos por Sioli (1965). Verificou-se a presença dessa bactéria em $45(67,16 \%)$ das 67 amostras. distribuidas por $15(75 \%)$ das 20 amostras de água clara, $21(65,6 \%)$ das 32 amostras de água preta e 9 $(60 \%)$ das 15 amostras de água branca.

\section{INTRODUÇÃO}

Chromobacterium violaceum é um microrganismo de gênero de filiação incerta da $8^{\text {a }}$ parte do Bergey's Manual of Determinative Bacteriology (Buchanan \& Gibbons, 1974). É um bastonete Gram-negativc, 0,6-0,9 por $1,5-3 \mu \mathrm{m}$; possuindo motilidade flagelar, polar e lateral, não formando esporos. É essencialmente heterotrófica, utilizando compostos orgânicos como nutrientes. Esse microrganismo $\in$ comum em água e solo de regiōes tropicais e ocasionalmente causa infecções no homem. $\mathrm{Na}$ literatura estão registrados 16 casos fatais por Chromobacterium violaceum, 9 dos quais em crianças (Ognibene \& Thomas, 1970) .

Desenvolve-se muito bem em um meio comum de peptona, é anaeróbio facultativo. desde que haja disponibilidade de nutrientes adequados. Mesófilos, com ótimo de temperatura situado entre $30^{\circ} \mathrm{C}$ e $35^{\circ} \mathrm{C}$, mínimo entre $10-15^{\circ} \mathrm{C}$, máximo $40^{\circ} \mathrm{C}$.

A falta quase completa de informações sobre a ocorrência e distribuição de Chromobacterium violaceum não deve ser devida à dificuldade no reconhecimento da mesma, pois esta bactéria é facilmente visualizada por formar colônias roxas, muito características. Essa ausência de dados parece ser, provavel- mente, devida à falta de métodos adequados para o isolamento e também ao fato de que são poucos os que estudam e pesquisam o assunto, em áreas tropicais. Produz um pigmento, a violaceína, caracterizado por ser insolúvel na água e no clorofórmio porém solúvel em acetona e álcool etílico, dando uma solução violeta. O teste para comprovar a violaceína em culture pura é simples e as reações obtidas são características, nấo se encontrando em qualquer outro pigmento bacteriano (Sneath, 1966).

$\mathrm{Na}$ bacia amazônica, Chromobacterium violaceum tem sido encontrada nos rios, lagos, igarapés e na água tratada de consumo das cidades.

Neste trabalho, procurou-se estabelecer a ocorrência e distribuição geográfica de Chromobacterium violaceum nas águas da Amazônia Central.

\section{MATERIAI E MÉTODOS}

Em 67 amostras de águas superficiais de rios, lagos e igarapés da Amazônia, foi estudada a ocorrência de Chromobacterium violaceum. As amostras foram classificadas como de água preta, branca ou clara, de acordo com as características físico-químicas

Baseado em resultados obtidos de uma série de experimentos anteriores (Skerman, (1967), foi usado o meio Plate Count Agar (Tryptone, Glucose Yeast Agar), que é um agar nutritivo onde o organismo cresce muito bem e cuja composição é: Glicose $1,0 \mathrm{~g}$. Peptona-Tryptone $5,0 \mathrm{~g}$. Yeast extract $2,5 \mathrm{~g}$. Agar $15,0 \mathrm{~g}$, água destilada $1000 \mathrm{ml}$ e $\mathrm{pH} 7,0 \pm 0,1$.

A inoculação foi feita pelo método de filtração, usando filtros de membrana Sartorius SM $14005,0(2 \mu$ de porosidade e $50 \mathrm{~m}$ de diâ-

(*) - Instituto Nacional de Pesquisas da Amazônia, Manaus. 
metro, ou com inoculação de $1 \mathrm{ml}$ da amostra, diretamente sobre o meio de cultura nas placas American Public Health Association, (1971). As placas assim preparadas foram incubadas a $37^{\circ} \mathrm{C}$ e após 24 horas contavam-se as colônias de Chromobacterium violaceum, caracterizadas pela cor roxa intensa, forma circular, lisas, algumas vezes rugosas, não gelatinosas. Normalmente, as colônias apareceram isoladas. Em alguns casos, apareceram colôinias contaminadas por outros microrganismos. Nestes casos, as amostras só foram consideradas positivas quando através de repiques era obtida uma cultura pura.

Foram testadas cepas encontradas no sistema de distribuição de água das cidades de Manaus e Belém, para verificar a resistência ao sulfato de alumínio e clorn. Para o teste de resistência ao sulfato de alumínio e cloro, utilizou-se uma solução-estoque de $2 \%$ de sulfato de alumínio (Usina Colombiana), em diluição de

$$
\frac{1}{10} \frac{1}{100} \cdot \frac{1}{1000} \text { e } \frac{1}{10000}
$$

Para o cloro, utilizou-se o HTH cloro seco (Olin Química Ltda.) em diluição de

$$
\frac{1}{10} \frac{1}{100} \frac{1}{1000}{ }^{\mathrm{e}} \frac{1}{10000} \text {. }
$$

Para verificar o efeito do $\mathrm{pH}$ do substrato sobre a crescimento bacteriano, foram feitos experimentos triplicados em Nutrient broth, basic nutrient media (Cowan \& Stell, 1965), com $\mathrm{pH}$ variando de $3,5-8,5$. Utilizou-se $10 \mathrm{ml}$ por tubo da solução nutritiva, esterilizada e os tubos inoculados em estufa a $37^{\circ} \mathrm{C}$ por 24 horas. Após esse período, os tubos foram analisados, relacionando o indice de crescimento com a absorção de luz em electrofotômetro ELKO II, com filtro S42E. Para zeragem do aparelho utilizou-se o meio estéril $e$ as diferenças de absorção e transmitância foram relacionados com crescimento e $\mathrm{pH}$.

Foi determinado o $\mathrm{pH}$ das águas pelo $\mathrm{pH}$ meter-Model LS, Sargent Welch e anotado o tipo de água de todas as amostras na ocasião da coleta, segundo as características dadas por Sioli (1965).
Resultados E Discussões

A maicr percentagem de amostras positivas foi encontrada na água clara, seguindo-se a água preta e com menor índice, a branca. $\mathrm{Na}$ Tabela I são apresentados os resultados das contagens de colônias de Chromobacterium violaceum (Fig. 1) nas 67 amostras de águas estudadas.

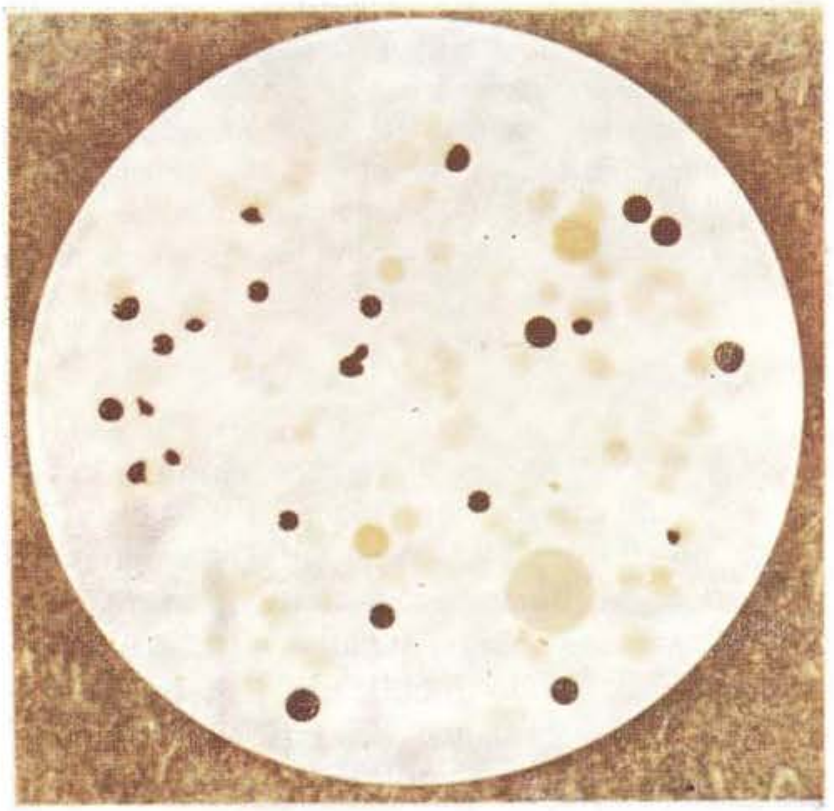

Fig. 1 - Aspecto das colônias de Chromobacterium violaceum em filtro de membrana.

Verifica-se em primeiro lugar, a presença de Chromobacterium violaceum em 45 $(67,16 \%)$ das amostras, sendo que 15 $(75,00 \%)$ das 20 amostras de água clara, 21 $(65,625 \%)$ das 32 amostras de água preta e 9 $(60,00 \%)$ das 15 amostras de água branca apresentavam a referida bactéria.

A Fig. 2 mostra comparativamente o efeito de água sobre o percentual de amostras positivas. Paralelamente, o número de colônias de Chromobacterium violaceum encontrado nas amostras de água, apresenta maior número na água clara, com uma média de 6,7 colônias por ml, seguindo-se a água preta com uma média de 6,1 colônias por $\mathrm{ml}$ e por último, a água branca que apresenta uma média de 3,1 colônias por $\mathrm{ml}$ (Fig. 3) . 
TABELA I - Ocorrência de Chromobacterium violaceum em 67 amostras de água nos corpos d'água do Amazônia Central

\begin{tabular}{|c|c|c|c|c|c|c|}
\hline Amostra & Mês & Local & $\begin{array}{l}\text { Rio } \\
\text { principal }\end{array}$ & $\begin{array}{l}\text { Tipo de } \\
\text { água }\end{array}$ & $\begin{array}{l}\text { Colônias do } \\
\text { C. violaceum } \\
\text { por } \mathrm{ml}\end{array}$ & $\mathrm{pH}$ \\
\hline 1 & Fevereiro & o Lago Anamã & Solimões & preta & 2 & 5.6 \\
\hline 2 & $"$ & "Anori & n & " & 0 & 5.2 \\
\hline 3 & 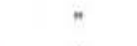 & - Bacuri & Negro & " & 1 & 6.2 \\
\hline 4 & " & " Caapiranga & Solimōes & - & 0 & 6.0 \\
\hline 5 & " & " Calado & $n$ & * & 0 & 6.2 \\
\hline 6 & " & " Cacau-Pirera & Negro & - & 3 & 5.8 \\
\hline 7 & * & Guedes & 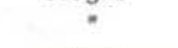 & - & 5 & 4.8 \\
\hline 8 & " & " Grande de Manacapuru & Solimōes & $\cdot$ & 0 & 5.4 \\
\hline 9 & * & " Jacaré & $\cdot$ & clara & 0 & 6.8 \\
\hline 10 & - & " Jaraqui & Negro & preta & 6 & 4.6 \\
\hline 11 & " & " Miriti & Solimões & clara & 0 & 6.8 \\
\hline 12 & $"$ & Rio Moju & Curuá-Una & preta & 7 & 5.4 \\
\hline 13 & " & Lago Muratu & Solimōes & 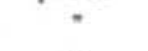 & 0 & 4.8 \\
\hline 14 & " & " Mururé & Purus & $"$ & 0 & 5.5 \\
\hline 15 & $"$ & " Pacova & Solimốes & branca & 2 & 7.1 \\
\hline 16 & " & " Passarinho & " & $\cdot$ & 3 & 6.9 \\
\hline 17 & $"$ & " Piranha & " & - & 0 & 7.0 \\
\hline 18 & $"$ & Rio Purus & $\cdot$ & $*$ & 3 & 5.0 \\
\hline 19 & * & " Tarumā-mirim & Negro & preta & 1 & 4.4 \\
\hline 20 & $"$ & Lago Surara & Purus & + & 0 & 4.6 \\
\hline 21 & " & " Xiborema & Solimōes & branca & 2 & 7.0 \\
\hline 22 & Março & Rio Curuá-Una & Amazonas & clara & 2 & 6.4 \\
\hline 23 & n & " Jutaí & Solimōes & preta & 0 & 6.0 \\
\hline 24 & " & " Juruá & 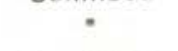 & branca & 0 & 7.1 \\
\hline 25 & " & - Mojuí & Curuá-Una & preta & 1 & 5.6 \\
\hline 26 & $"$ & " Solimōes & Amazonas & branca & 2 & 7.5 \\
\hline 27 & " & " Tefé & Sclimöes & preta & 0 & 6.6 \\
\hline 28 & " & " Uarini & $n$ & $\cdot$ & 6 & 6.1 \\
\hline 29 & Abril & Lago Cristalino & Negro & clara & 6 & 5.3 \\
\hline 30 & $"$ & Rio Aripuanã & Madeira & $*$ & 3 & 6.7 \\
\hline 31 & $n$ & $\begin{array}{l}\text { - Aripuanã (depois da cachoeira das An- } \\
\text { dorinhas) }\end{array}$ & " & * & 12 & 7.2 \\
\hline 32 & 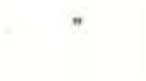 & $\begin{array}{l}\text { Córrego da cachoeira das Andorinhas } \\
\text { Río Aripuanā (depois da cachoeira de Da:- }\end{array}$ & - & - & 3 & 7.1 \\
\hline 33 & - & & $"$ & " & Incontáveis & 7.1 \\
\hline 34 & $"$ & " Aripuanã (igapó) & 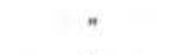 & $\cdot$ & 7 & 7.1 \\
\hline 35 & " & " Aripuanã (ıgarapé) & " & preta & 10 & 6.6 \\
\hline 36 & " & " Aripuanã (baia) & " & * & 4 & 6.8 \\
\hline 37 & 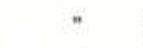 & Córrego da Floresta na estrada da Pocilga & Aripuanä & clara & 37 & 7.2 \\
\hline 38 & - & Cachoeira que é captada para a Pocilga & $n$ & $\cdot$ & 9 & 7.3 \\
\hline 39 & " & Igarapé Cuxiual & " & $=$ & 1 & 7.0 \\
\hline 40 & " & Lago Grande do Manaquiri & Solimōes & branca & 0 & 6.9 \\
\hline 41 & Junho & S. Sebastiâo & 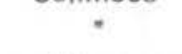 & preta & 3 & 8.1 \\
\hline 42 & Julho & Rio Cuieiras & Negro & $\because$ & 0 & 5.8 \\
\hline 43 & $"$ & Lago Manacapuru & Solimōes & ciara & 1 & 6.6 \\
\hline 44 & $\cdot$ & Rio Negro & Amazonas & preta & 28 & 6.2 \\
\hline 45 & Agosto & Lago Aleixo & 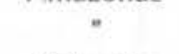 & branca & 12 & 6.8 \\
\hline 46 & " & " Baixio & Solimões & 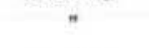 & 0 & 6.5 \\
\hline $47^{\circ}$ & " & Rio Camanau & Negro & preta & 3 & 4.8 \\
\hline 48 & * & Lago Grande Jutai & Solimōes & clara & 0 & 6.3 \\
\hline
\end{tabular}




\begin{tabular}{|c|c|c|c|c|c|c|c|}
\hline Amostra & Mês & & Local & $\begin{array}{c}\text { Rio } \\
\text { principal }\end{array}$ & $\begin{array}{c}\text { Tipo de } \\
\text { água }\end{array}$ & $\begin{array}{l}\text { Colônias de } \\
\text { C. violaceum } \\
\text { por } \mathrm{m} \text { ! }\end{array}$ & $\mathrm{pH}$ \\
\hline 49 & $"$ & " Jacaretinga & & $"$ & branca & 0 & 6.4 \\
\hline 50 & " & " Janauari & & Negro & " & 1 & 5.5 \\
\hline 51 & $n$ & Rio Jau & & " & preta & 0 & 5.0 \\
\hline 52 & $"$ & Lago Muru-muru & & Solimöes & clara & 0 & 6.5 \\
\hline 53 & $n$ & Patos & & $n$ & " & 0 & 6.3 \\
\hline 54 & n & " Tupé & & Negro & preta & 8 & 5.8 \\
\hline 55 & Setembro & Rio Abonari & & n & $"$ & 20 & 4. 5 \\
\hline 56 & $n$ & Igarapé do Acará & & " & $n$ & 9 & 4.8 \\
\hline 57 & $"$ & " Barro Branco & & $"$ & a & 4 & 4.9 \\
\hline 58 & $"$ & Rio Branquinho & & $"$ & pranca & 2 & 65 \\
\hline 59 & " & " Jundiá & & $n$ & preta & 1 & 4.9 \\
\hline 60 & Outubro & Lago Āgua Preta & & Guamá & clara & 5 & 5.6 \\
\hline 61 & " & " bolonha & & " & $"$ & 3 & 6.0 \\
\hline 62 & $n$ & " Estábulo & & $n$ & $"$ & 4 & 5.8 \\
\hline 63 & $n$ & Rio Guamá & & Amazonas & " & 3 & 6.2 \\
\hline 64 & " & Lago dos Reis & & " & branca & 0 & 6.6 \\
\hline 65 & Dezembro & Aruaú & & Negro & preta & 3 & 4.8 \\
\hline 66 & " & " Castanho & & Solimôes & branca & 1 & 7.3 \\
\hline 67 & $n$ & Igarapé do Paraná d & a Terra Preta & Negro & preta & 5 & 4.5 \\
\hline
\end{tabular}

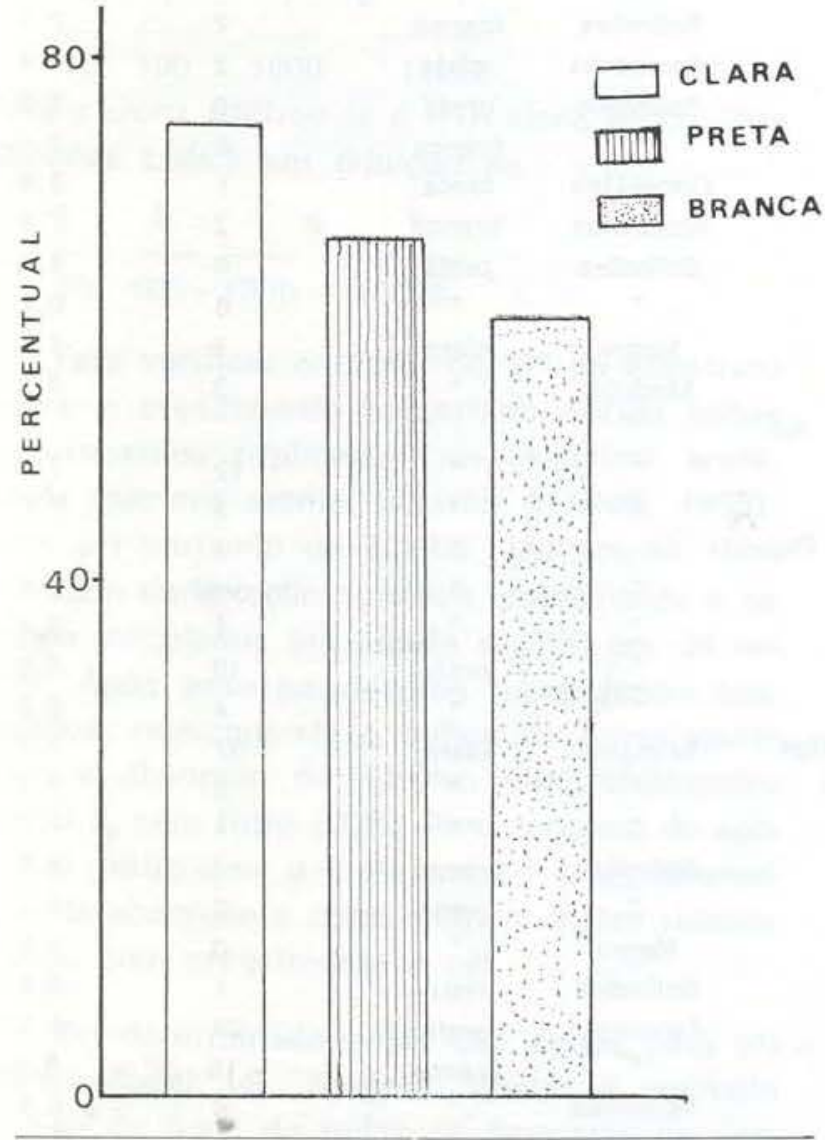

Fig. 2 - Efeito de tipos de águas na Amazônia na ocorrência de Chromobacterium violaceum.

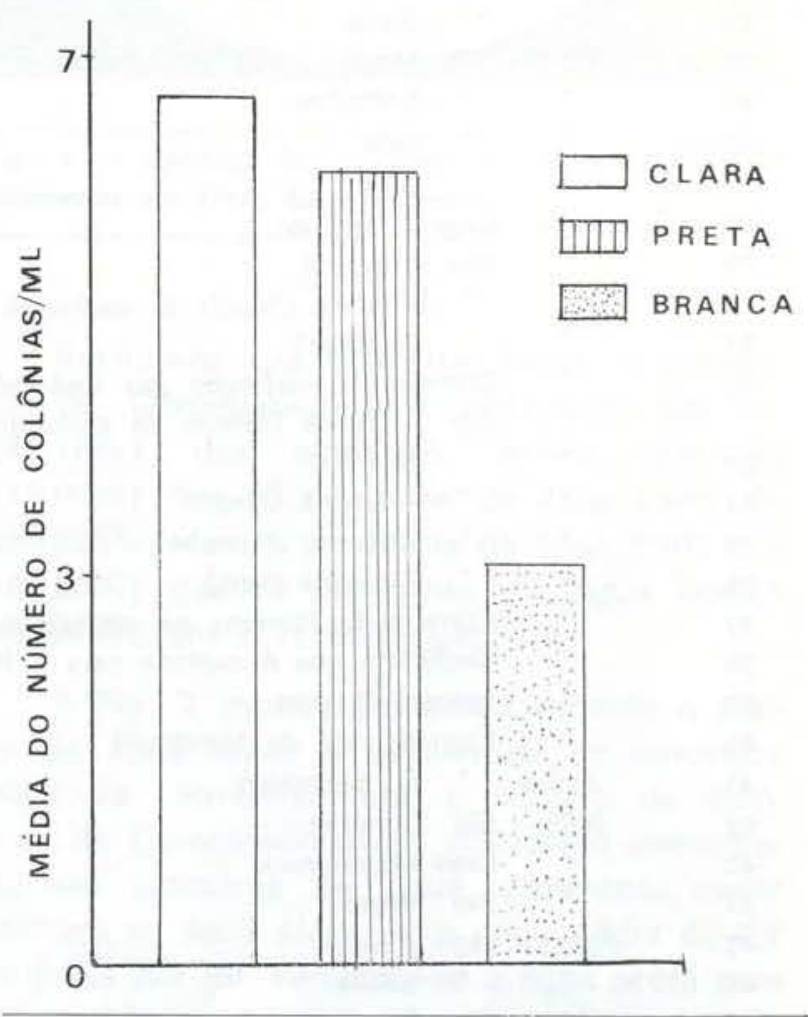

Fig. 3 - Média do número de colônias/ml de Chromobacterium violaceum encontredo nas águas dá Amazônia 
Chromobacterium violaceum não é uma bactéria muito exigente para desenvolver-se em meios de cultura e tolera valores variados de $\mathrm{pH}$, crescendo em meios com $\mathrm{pH}$ variando desde 4,4 à 8,8 , sendo que em 5,8 , atinge 0 melhor crescimento (Fig. 4).

Das amostras de água coletadas, notou-se a presença de Chromobacterium violaceum nas águas com $\mathrm{pH}$ de 4,4 a 8,4 , porém, o maior percentual de amostras positivas foi na faixa de $5,5-6,9$ (Fig. 5).

Um outro resultado a comentar é a resistência da bactéria à presença de sulfato de alumínio e ao cloro, que são os elementos usados para o tratamento de águas nas cidades de Belém e Manaus. Verificou-se que a partir da diluição de 1 da solução estoque $100^{-}$

de $2 \%$ de sulfato de alumínio, a bactéria co-

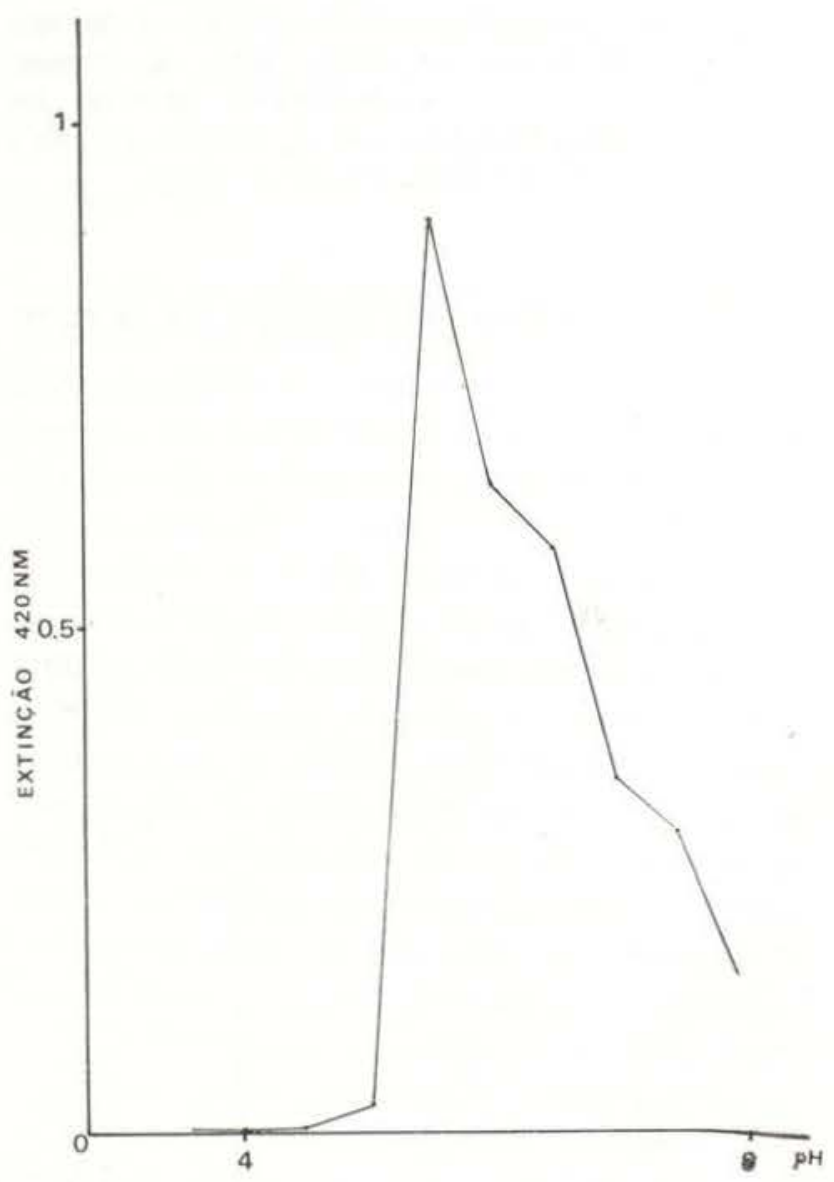

Fig. $=4$ - Relação do $\mathrm{pH}$ com a extinção dada pelo crescimento de Chromobacterium violaceum (média de três experimentos).

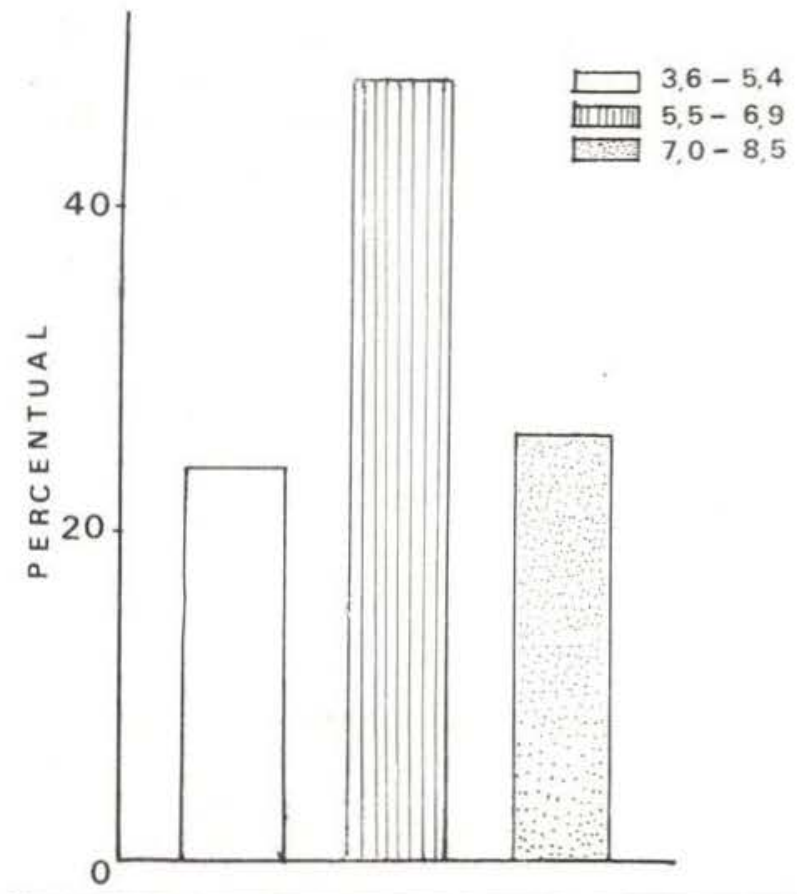

Fig. 5 - Efeito do $\mathrm{pH}$ na ocorrência de Chromobacte. rium violaceum.

meça a desenvolver-se, a mesmo ocorrendo com a diluição de cloro. Em soluções mais 11 concentradas $\left(\frac{1}{1}, \frac{1}{10}\right)$ näo se obteve desenvolvimento observável.

Os dados apresentados no presente trabatho demonstram que realmente a bactéria ocorre nos corpos d'água da Amazônia Central, com bastante freqüência. De qualquer forma, o estudo da distribuição e ocorrência de Chromobacterium violaceum é de grande importância devido à capacidade desta bactéria de produzir um pigmento que tem sido objeto de estudos em vários campos da Biologia.

\section{CONCLUSÕES}

Os resultados obtidos neste estudo preliminar permitem as seguintes conclusōes:

a) a distribuição e ocorrência de Chromo bacterium violaceum na Amazônia Central é bastante freqüente, provavelmente ligada às condiçōes tropicais;

b) o maior número de colônias por $\mathrm{ml}$ nas amostras positivas, a maior percentagem de amostras positivas e o $\mathrm{pH}$ ótimo de Chromo- 
bacterium violaceum convergem todos para os parâmetros estabelecidos para água clara, embora ela possa ocorrrer em qualquer corpo d'água.

\section{AGRADECIMENTOS}

Ao Dr. Ozório J. de M. Fonseca, pela orientação e incentivo durante o desenvolvi. mento deste trabalho, assim como pela correcão do mesmo.

\section{SUMMARY}

The occurrence of Chromobacterium violaceum was investigated in the surface waters of rivers, lakes and streams of the Central Amazon Region. The bodies of waters proposed by Sioli (1965). Chromobacterium violaceum was observed in $45(67,16 \%)$ of the total 67 samples being in $15(75,00 \%)$ of the 20 clearwater samples, $21(65,6 \%)$ of the 32 black water samples and $9(60,00 \%)$ of the 15 with water samples.

\section{BIBLIOGRAFIA}

American Public Health Association

1971 - Standard Methods for the Examination of water and wastewater. $13 \mathrm{ed}, 874 \mathrm{p}$.
Buchanan, R.E. \& Gibbons, N.E.

1974 - Bergey's Manual of Determinative Bacteriology. 8 ed., Baltimore, Williams and Wilkins. 1246 p.

COWAN, S.T. \& Steel, K.J.

1965 - Manual for the identification of Medical bacteria. Cambridge. University Press. $217 \mathrm{p}$.

Ognibene, A.J. \& Thomas, E.

1970 - Fatal infection due to Chromobacterium violaceum in Vietnam. American Journal of Clinical Pathology, $54: 607-610$.

SIOLI, H.

1967 - Studies in Amazonian Waters - IN: Atas do Simpósio sobre a Biota Amazônica, 3 (Limnologia) : 9-50.

SKERMAN, V.B.D.

1967 - A guide to the identification of genera of Bacteria. 2 ed. Baltimore, Williams and Wilkins, $303 \mathrm{p}$

SNEATH, P.H.A

1966 - Identification methods applied to Chromobacterium. In: Gibbs, B.M. \& Skinner, F.A. eds. - Identification Methods for Microbiologists, part A. London and New York, Academic Press. p. 15-20.

(Aceito para publicação em 20/02/79) 